\title{
A Fluorescently Ratiometric Natural Probe for Selective Detection of Sulfur Dioxide Derivative and Host-Guest Supramolecular Regulation
}

\author{
Xingyu Tong, Ting Ye, Yali Yu, Longlong Gao, Yifan FeI, Qingqing Zhang, Heng GaO, \\ Chenxiao Yan, and Yong SHaO ${ }^{\dagger}$ \\ Institute of Physical Chemistry, College of Chemistry and Life Sciences, Zhejiang Normal University, \\ Jinhua 321004, Zhejiang, China
}

\begin{abstract}
Natural sanguinarine (SG) was first used as a fluorescent probe to develop a novel ratiometric sensor for selective $\mathrm{HSO}_{3}{ }^{-}$detection. The nucleophilic addition reaction of $\mathrm{HSO}_{3}{ }^{-}$occurs at the $\mathrm{C}=\mathrm{N}^{+}$group of $\mathrm{SG}$, and subsequent breakage of the conjugated $\pi$ cycle leads to a decrease in the SG iminium fluorescence that is accompanied by an increase in the alkanolamine fluorescence. Therefore, a ratiometric fluorescence method with a large wavelength shift can be established for $\mathrm{HSO}_{3}{ }^{-}$detection. Furthermore, cucurbit[8]uril was used as an efficient host to encapsulate SG for an improved selectivity for $\mathrm{HSO}_{3}{ }^{-}$detection over $\mathrm{H}_{2} \mathrm{~S}$. Our method benefits include little interference from other common anions and cations for $\mathrm{HSO}_{3}{ }^{-}$detection, suggesting a promising application in real sample analysis. Besides sensor development, the interaction of the natural SG with $\mathrm{HSO}_{3}{ }^{-}$was first demonstrated in this work to further get an insight into SG's pharmacology.
\end{abstract}

Keywords Sanguinarine, ratiometric fluorescence, $\mathrm{HSO}_{3}{ }^{-}$, detection, cucurbit[8]uril, selectivity

(Received September 23, 2019; Accepted October 21, 2019; Advance Publication Released Online by J-STAGE November 1, 2019)

\section{Introduction}

As major environmental pollutants, $\mathrm{SO}_{2} / \mathrm{H}_{2} \mathrm{~S}$ derivatives (including sulfurous acid $\left(\mathrm{H}_{2} \mathrm{SO}_{3}\right)$, sulfite $\left(\mathrm{SO}_{3}{ }^{2-}\right)$, bisulfite $\left(\mathrm{HSO}_{3}{ }^{-}\right)$, hydrogen sulfide $\left(\mathrm{H}_{2} \mathrm{~S}\right)$, sulfion $\left(\mathrm{S}^{2-}\right)$, etc. $)$ can cause heavy damages to the ecological environment and human health, especially with a long-term exposure. ${ }^{1-6}$ To prevent oxidation, some foods and beverages are stored also using sodium sulfite as an efficient preservative. However, asthma and other allergic symptoms can arise with an excess of sulfite involved in foods and beverages. ${ }^{7}$ Furthermore, it is accepted that endogenous $\mathrm{SO}_{2}$ and its derivatives in mammals can modulate a wide range of physiological processes. ${ }^{8}$ Therefore, there is great demand to develop a straightforward method for reliable detection of $\mathrm{SO}_{2}$ derivatives.

Variant fluorescent probes have been utilized for the detection of $\mathrm{SO}_{2}$ derivatives by nucleophilic addition to double bonds $(\mathrm{C}=\mathrm{O}, \mathrm{C}=\mathrm{C}, \mathrm{C}=\mathrm{N}$, and $\mathrm{N}=\mathrm{N})$, reduction of azide, nitryl, and selenoxide groups, and the Michael addition reaction. ${ }^{3-5,9,10}$ The probes with fluorescent ratiometric responses have received much attention due to their ability to eliminate fluctuations of the measuring environments by self-calibration. Special efforts must be made to synthesize the ratiometric probes. For example, fluorophores with the levulinate moiety can be selectively deprotected by $\mathrm{SO}_{3}{ }^{2-} / \mathrm{HSO}_{3}{ }^{-}$to allow the occurrence of excitedstate intramolecular proton transfer (ESIPT) or internal charge transfer (ICT) with a subsequent red-shifted emission. ${ }^{11-13}$ The nucleophilic addition of $\mathrm{SO}_{3}{ }^{2-} / \mathrm{HSO}_{3}{ }^{-}$to double bonds interrupts the intramolecular charge-transfer (ICT) process or the fluorescence resonance energy transfer (FRET) process, which leads to a ratiometric change of the fluorescence signal. ${ }^{14-19}$ However, developing ratiometric probes for selective $\mathrm{SO}_{3}{ }^{2-} / \mathrm{HSO}_{3}$ detection without an elaborate synthesis procedure, but with a large emission wavelength shift, is still under the way.

We have continued to search for natural products that have selective molecular-recognition capacities ${ }^{20-23}$ along with promising theranostic potentials. Sanguinarine (SG), a natural benzophenanthridine alkaloid, is well known for its antitumor property and cancer treatment. ${ }^{24-28}$ It has been reported that the $\mathrm{C} 6=\mathrm{N} 5^{+}$double bond in $\mathrm{SG}$ can be attacked by a nucleophilic reagent (for example, $\mathrm{OH}^{-}$) towards converting the positively charged iminium form to the alkanolamine form (Scheme 1)..$^{20,29,30}$ These two forms emit at two bands with a wavelength separation of at least $100 \mathrm{~nm}$. Therefore, $\mathrm{SG}$ can serve as a natural ratiometric probe for the straightforward $\mathrm{SO}_{2}$ derivative detection without any elaborate probe synthesis procedure. In this work, we first investigated the possibility of SG interacting with $\mathrm{HSO}_{3}{ }^{-}$for $\mathrm{HSO}_{3}{ }^{-}$detection by converting the iminium form to the alkanolamine form. Interestingly, the supramolecular encapsulation of SG with cucurbit[8]uril $(\mathrm{CB}[8])^{31}$ can improve the selectivity for $\mathrm{HSO}_{3}{ }^{-}$detection.

$\dagger$ To whom correspondence should be addressed.

E-mail: yshao@zjnu.cn 


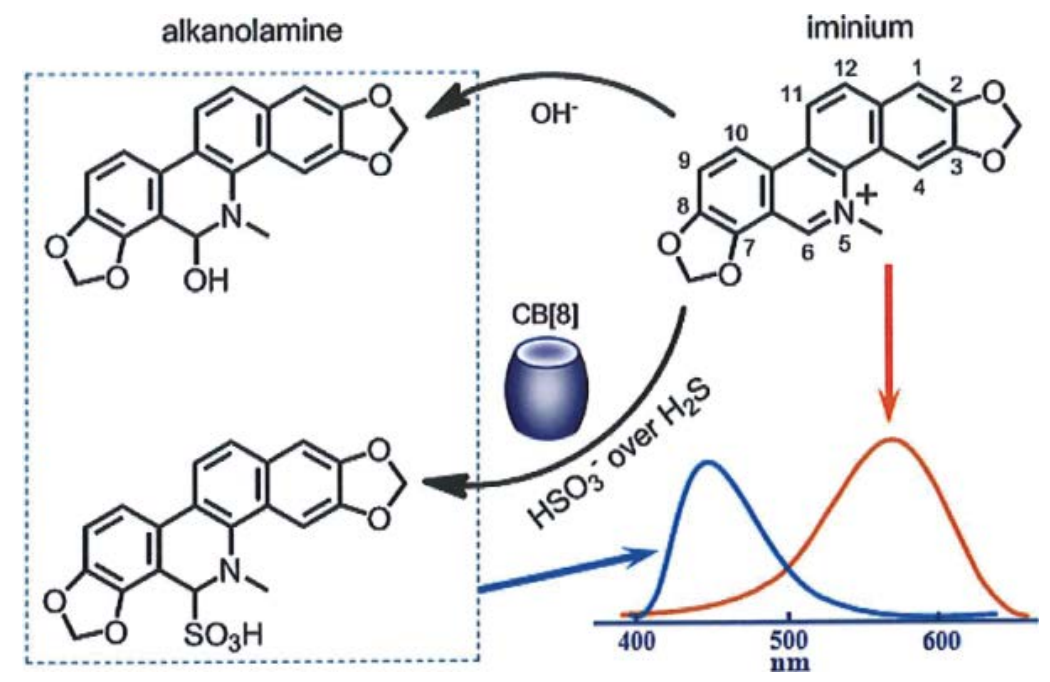

Scheme 1 Structure conversion of SG from the iminium form to the alkanolamine form upon its interaction with $\mathrm{OH}^{-}$(at alkalic solution) and $\mathrm{HSO}_{3}^{-}$(at acidic solution) following the emission wavelength shifts. The $\mathrm{CB}[8]$ binding with the iminium form of SG highly favors the nucleophilic addition of $\mathrm{HSO}_{3}{ }^{-}$over $\mathrm{H}_{2} \mathrm{~S}$.

\section{Experimental}

\section{Reagents and chemicals}

Cucurbit $[n]$ urils $(\mathrm{CB}[n], n=5,6,7,8)$ were purchased from Strem Chemicals, Inc. (MA, USA). SG and metal ions were purchased from Aladdin Reagent Co. (Shanghai, China). $\mathrm{Na}_{2} \mathrm{SO}_{3}$ and $\mathrm{Na}_{2} \mathrm{~S}$ (Sinopharm Chemical Reagent Co., Ltd, Shanghai, China) were used as the sulfur-containing species. At the optimized $\mathrm{pH} 6.2$, they exist mainly at $\mathrm{HSO}_{3}{ }^{-}$and $\mathrm{H}_{2} \mathrm{~S}\left(\mathrm{p} K_{\mathrm{a} 1}\right.$ and $\mathrm{p} K_{\mathrm{a} 2}$ for $\mathrm{H}_{2} \mathrm{SO}_{3}$ are about 1.9 and 7.2, while those for $\mathrm{H}_{2} \mathrm{~S}$ are about 6.9 and 14.1, respectively). In this work, for convenience, we nominate them as $\mathrm{HSO}_{3}{ }^{-}$and $\mathrm{H}_{2} \mathrm{~S}$ throughout the text, although they should not exist in these states at $\mathrm{pH}$, other than 6.2. Other reagents were of analytical grade (Sinopharm Chemical Reagent Co., Ltd, Shanghai, China) and used without any purification. Milli-Q water (18.2 M 2 ; Millipore Co, Billerica, USA) was used in all of the experiments.

\section{Fluorescence measurements}

Fluorescence spectra were acquired with a F-2700 spectrofluorometer (Hitachi High-Technology Corp, Japan). The fluorescence was measured in a quartz cell with a path length of $1 \mathrm{~cm}$ under excitation at $327 \mathrm{~nm}$. SG at the specified concentration was added into the solution buffered with $50 \mathrm{mM}$ PBS $\left(0.1 \mathrm{M} \mathrm{K}^{+}\right)$at the specified $\mathrm{pH}$, and the resulting solutions were allowed to incubate for $30 \mathrm{~min}$ before the addition of $\mathrm{CB}[n]$. Fluorescence measurements were measured at $20^{\circ} \mathrm{C}$ after incubating the resultant solution with $\mathrm{HSO}_{3}^{-}$or other species for $30 \mathrm{~min}$.

\section{Absorption spectra measurements}

Absorption spectra were determined with a UV2550 spectrophotometer (Shimadzu Corp., Japan), equipped with a temperature-controlled circulator (Julabo Labortechnik GmbH, Seelbach, Germany) at $20^{\circ} \mathrm{C}$ and a quartz cell with a path length of $1 \mathrm{~cm}$.

\section{${ }^{1} H$ NMR experiments}

${ }^{1} \mathrm{H}$ NMR experiments were acquired with a Bruker Avence
$600 \mathrm{MHz}$ NMR spectrometer. Samples were prepared by dissolving SG in $0.5 \mathrm{~mL} \mathrm{D}_{2} \mathrm{O}(4 \mathrm{mM})$. After NMR scanning, $20 \mathrm{mM} \mathrm{HSO}_{3}{ }^{-}$was then added to allow incubation for $30 \mathrm{~min}$ before the NMR measurements.

\section{Sample detection}

Tap water and rainwater samples were determined using the standard addition method. The final SG and $\mathrm{CB}[8]$ concentrations were maintained at 1 and $5 \mu \mathrm{M}$, respectively. Into the water samples were added PBS buffer $(50 \mathrm{mM}, 0.1 \mathrm{M}$ $\mathrm{K}^{+}, \mathrm{pH}$ 6.2) containing $\mathrm{SG}$ and $\mathrm{CB}[8]$ before a fluorescence measurement. Then, an appropriate $\mathrm{Na}_{2} \mathrm{SO}_{3}$ standard was added to allow incubation for 30 min before recording the fluorescence. The calibration curve was used to obtain the recovery and sample results.

\section{Results and Discussion}

In aqueous solution, $\mathrm{SG}$ exists in the iminium and alkanolamine forms with their populations dependent on the $\mathrm{pH}^{20,29,30}$ As shown in Fig. 1A, increasing the solution pH (from 4.5 to 9.2) causes an increase in the alkanolamine emission band $\left(F_{\mathrm{a}}\right)$ as well as a decease in the iminium emission band $\left(F_{\mathrm{i}}\right)$ of $1 \mu \mathrm{M} \mathrm{SG}$ because of an $\mathrm{OH}^{-}$attack with the C6=N5 ${ }^{+}$bond (Scheme 1). ${ }^{18,29,30}$ The $F_{\mathrm{a}}$ band at $409 \mathrm{~nm}$ and the $F_{\mathrm{i}}$ band at $565 \mathrm{~nm}$ can be obtained with excitation at $327 \mathrm{~nm} .{ }^{20}$ The fluorescence intensity at $409 \mathrm{~nm}$ as a function of the $\mathrm{pH}$ predicts a $\mathrm{p} K_{\mathrm{a}}$ of about 7.6 (Fig. 1D), which is in good agreement with previous reports..$^{20,29,30}$ Such a large emission wavelength shift $(156 \mathrm{~nm})$ due to breakage of the conjugated $\pi$ cycle (Scheme 1 ) is advantageous in developing novel sensors with an ideal contrast in signal response, although up to now, only the nucleophilic addition reaction of $\mathrm{OH}^{-}$has been investigated. In this work, we tried to use this property to develop a fluorescent sensor for selective detection of $\mathrm{HSO}_{3}{ }^{-}$. To regulate the response behavior of SG towards $\mathrm{HSO}_{3}^{-}$, we also investigated the supramolecular host-guest interaction of SG by complexation with cucurbit $[n]$ urils $(\mathrm{CB}[n], n=5,6,7,8)$ at $\mathrm{pH}$ 6.2. SG mainly exists in the iminium form at this condition. We found that $\mathrm{CB}[8]$ cavity is 

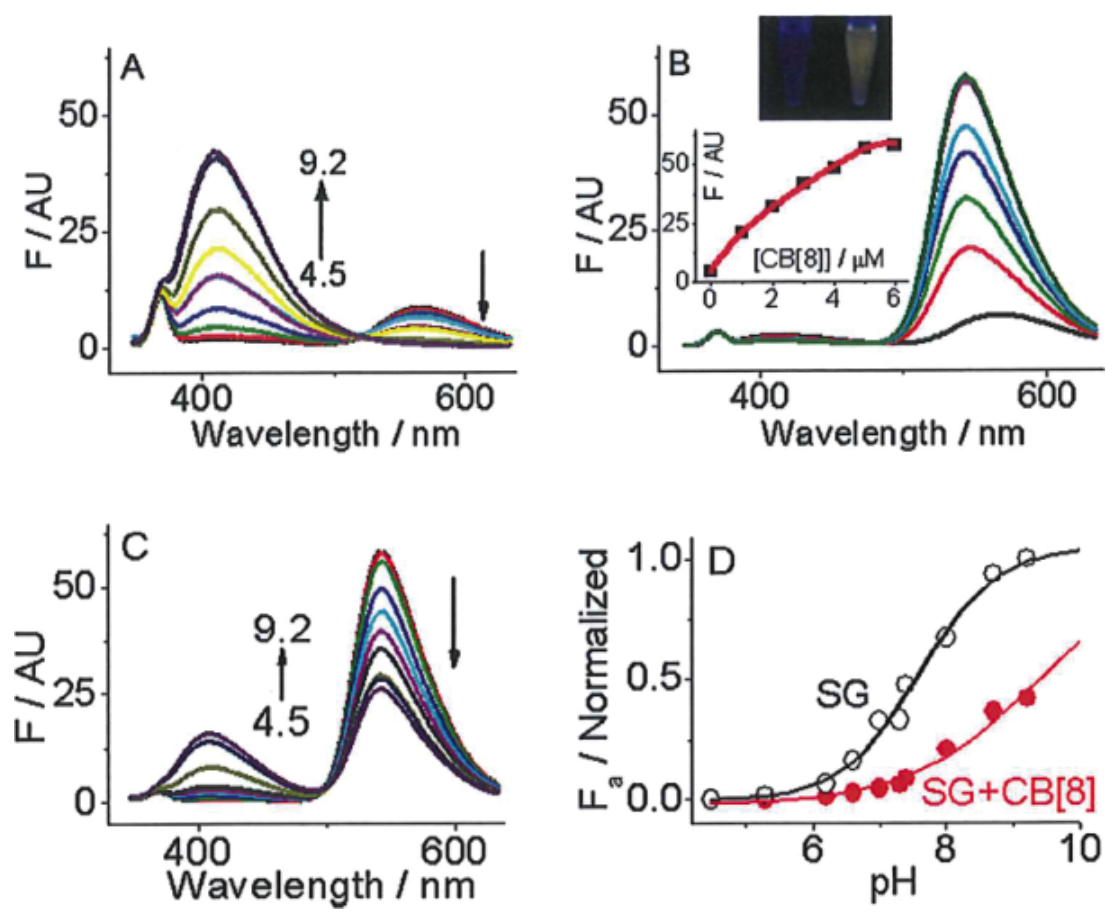

Fig. 1 Effect of the solution $\mathrm{pH}$ on the emission spectra of $1 \mu \mathrm{M} \mathrm{SG}$ in $50 \mathrm{mM}$ PBS $\left(0.1 \mathrm{M} \mathrm{K}^{+}\right)$in the (A) absence and (C) presence of $5 \mu \mathrm{M} \mathrm{CB}[8]$. (B) Fluorescence spectra of SG $(1 \mu \mathrm{M})$ in $50 \mathrm{mM}$ PBS $\left(0.1 \mathrm{M} \mathrm{K}^{+}, \mathrm{pH} 6.2\right)$ upon increasing the $\mathrm{CB}[8]$ concentration. Inset: Fluorescence intensity at $544 \mathrm{~nm}$ upon increasing the $\mathrm{CB}[8]$ concentration and photographs under UV illumination in the (left) absence and (right) presence of $5 \mu \mathrm{M} \mathrm{CB}[8]$. (D) Dependence of the fluorescence intensity at $409 \mathrm{~nm}\left(F_{\mathrm{a}}\right)$ on the solution $\mathrm{pH}$ in the absence and presence of $\mathrm{CB}[8]$.

the best host in lighting up the SG fluorescence (Fig. S1), although $\mathrm{CB}$ [7] has also been reported to be able to encapsulate $\mathrm{SG}^{31-33}$

As shown in Fig. 1B, at $\mathrm{pH} \mathrm{6.2,} \mathrm{increasing} \mathrm{the} \mathrm{CB}[8]$ concentration up to $6 \mu \mathrm{M}$ shifts the emission band of SG $(1 \mu \mathrm{M})$ from 565 to $544 \mathrm{~nm}$, accompanying a final 12-fold fluorescence increase. This host-guest interaction can be confirmed by the solution color change under UV illumination (inset of Fig. 1B). This indicates that the $\mathrm{CB}[8]$ cavity provides a hydrophobic microenvironment to protect SG from attacking by water molecules and other species, since SG at pH 6.2 is positively charged, as confirmed by other SG analogues with a solvent polarity-sensitive fluorescence behavior. ${ }^{34} \mathrm{pH}$-dependent experiments with $\mathrm{CB}$ [8] (Fig. 1C) show that the iminium form still remains, even increasing the solution $\mathrm{pH}$ to 9.2, suggesting a strong binding of the $\mathrm{SG}$ iminium form with $\mathrm{CB}[8]$ and inhibition of the nucleophilic interaction of $\mathrm{OH}^{-}$to produce the alkanolamine form. For example, at $\mathrm{pH}$ 9.2, the fluorescence of the SG alkanolamine form in the presence of $\mathrm{CB}[8]$ is 2.4-fold lower than that obtained in the absence of $\mathrm{CB}[8]$. Since $\mathrm{CB}[n]$ has a weak binding with the SG alkanolamine form ${ }^{32}$ and the fluorescence of the alkanolamine form is not strongly affect by $\mathrm{CB}[8]$, we can estimate that at $\mathrm{pH} 9.2$, only $42 \%$ SG (totally $1 \mu \mathrm{M})$ is converted to the alkanolamine form in the presence of $5 \mu \mathrm{M} \mathrm{CB}[8]$. Because the used PBS buffer can't be extended to a higher $\mathrm{pH}$, we extrapolated the $\mathrm{p} K_{\mathrm{a}}$ value of the $\mathrm{CB}[8]$-bound SG to be about 9.4, which is about $1.8 \mathrm{p} K_{\mathrm{a}}$ unit higher than that obtained without $\mathrm{CB}[8]$. However, a $\mathrm{p} K_{\mathrm{a}}$ shift of 3.7 has been observed in a previous report for the SG encapsulation by $\mathrm{CB}$ [7] in water solution without a substantial amount of cation ions. ${ }^{32}$ This is caused by the high ion strength of $0.1 \mathrm{M} \mathrm{K}^{+}$used in this work thus to weaken the encapsulation binding with $\mathrm{CB}[n]$ due to the competitive electrostatic binding of cation ions with the electronegative portals of $\mathrm{CB}[n] .{ }^{35}$ On the other hand, this hostguest encapsulation will decrease the background fluorescence in developing a SG-based ratiometric sensor when operating in a weakly acidic solution at which $\mathrm{SO}_{2}$ can exist dominantly as $\mathrm{HSO}_{3}{ }^{-}\left(\mathrm{p} K_{\mathrm{a} 1}\right.$ and $\mathrm{p} K_{\mathrm{a} 2}$ for $\mathrm{H}_{2} \mathrm{SO}_{3}$ are about 1.9 and 7.2). For example, at $\mathrm{pH} 6.2$, the presence of $\mathrm{CB}[8]$ leads to a 6.8 -fold decrease in the fluorescence of the alkanolamine form (Fig. 1D). We thus used pH 6.2 as the optimal buffer condition to prevent the $\mathrm{OH}^{-}$reaction with $\mathrm{SG}$.

We then measured the fluorescence response of SG $(1 \mu \mathrm{M})$ to $\mathrm{HSO}_{3}{ }^{-}$and $\mathrm{H}_{2} \mathrm{~S}$ at pH 6.2 with their concentrations up to $300 \mu \mathrm{M}$. As shown in Fig. 2A, the addition of $\mathrm{HSO}_{3}{ }^{-}$causes a decrease in the iminium band at $565 \mathrm{~nm}$ and an increase in the alkanolamine band, but appearing at $435 \mathrm{~nm}$. This suggests a specific interaction of $\mathrm{SG}$ with $\mathrm{HSO}_{3}{ }^{-}$to produce a product different from the reaction occurring with $\mathrm{OH}^{-}$(Scheme 1). Note that this $130 \mathrm{~nm}$ emission wavelength shift provides an ideal contrast in developing a ratiometric method for $\mathrm{HSO}_{3}$ detection, as confirmed by the clear color change under UV illumination (inset of Fig. 2A). The fluorescence ratio at 435 and $565 \mathrm{~nm}\left(F_{\mathrm{a}} / F_{\mathrm{i}}\right)$ is linear to the $\mathrm{HSO}_{3}{ }^{-}$concentration between 0 and $30 \mu \mathrm{M}$ (Fig. 2E). The detection limit is estimated to be about $1.2 \mu \mathrm{M}$, assuming a signal-to-noise ratio of 3 . However, addition of $\mathrm{H}_{2} \mathrm{~S}$ within the same concentration range similarly leads to the alkanolamine band emitting, but at $430 \mathrm{~nm}$, and brings smaller $F_{\mathrm{a}} / F_{\mathrm{i}}$ values (Fig. 2B). Within the linear response range, the response slope $\left(\Delta\left(F_{\mathrm{a}} / F_{\mathrm{i}}\right) v s . \Delta C\right)$ for $\mathrm{HSO}_{3}{ }^{-}$is only 11-fold higher than that for $\mathrm{H}_{2} \mathrm{~S}$ (Fig. 2E). These facts suggest that $\mathrm{HSO}_{3}{ }^{-}$has a stronger nucleophilic addition reaction with $\mathrm{SG}$ compared to $\mathrm{H}_{2} \mathrm{~S}$ (Scheme 1), most likely because of the higher electron density of the sulfur atom in $\mathrm{HSO}_{3}{ }^{-}$. 

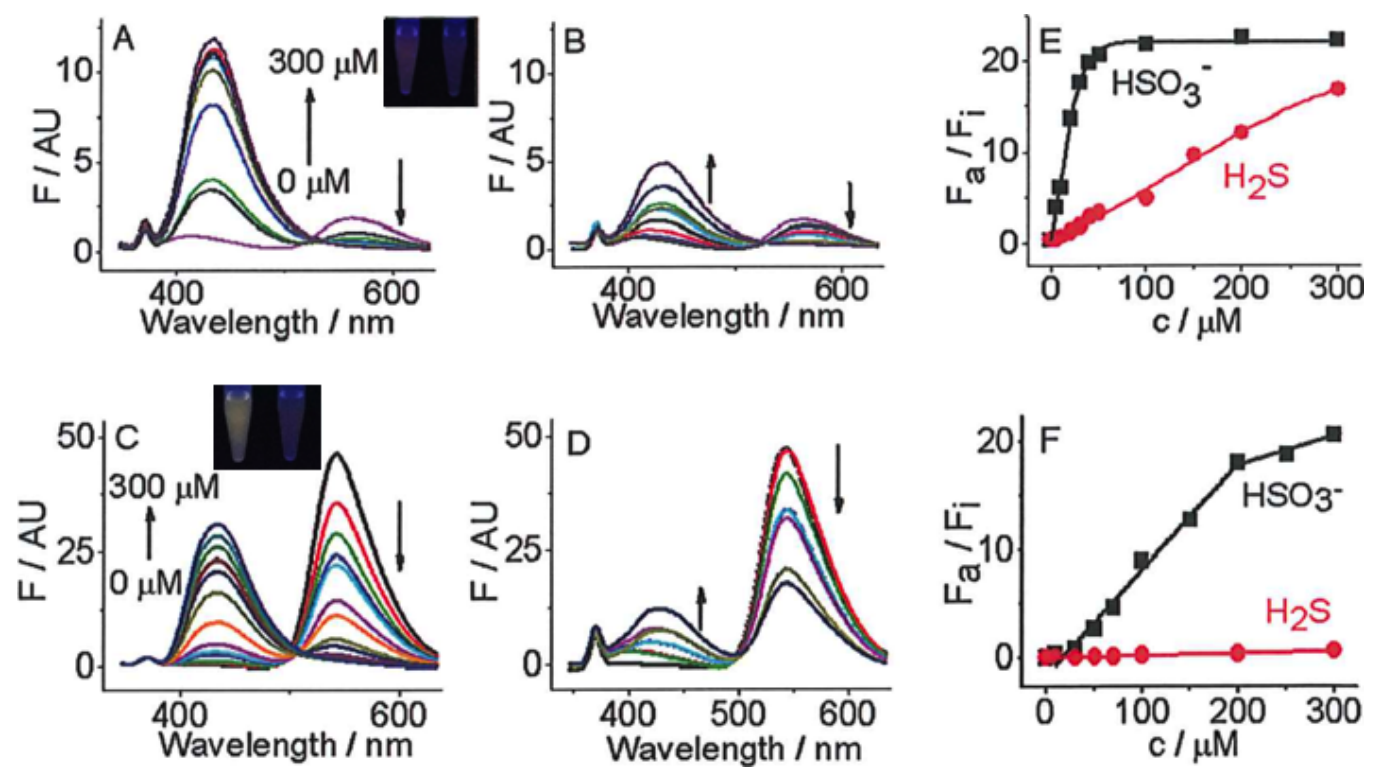

Fig. 2 Fluorescence spectra of SG $(1 \mu \mathrm{M})$ in $50 \mathrm{mM}$ PBS $\left(0.1 \mathrm{M} \mathrm{K}^{+}, \mathrm{pH}\right.$ 6.2) upon increasing the concentration of $(\mathrm{A}, \mathrm{C}) \mathrm{HSO}_{3}{ }^{-}$or $(\mathrm{B}, \mathrm{D}) \mathrm{H}_{2} \mathrm{~S}$ in the $(\mathrm{A}, \mathrm{B})$ absence and $(\mathrm{C}, \mathrm{D})$ presence of $5 \mu \mathrm{M} \mathrm{CB}[8]$, respectively. Photographs under UV illumination in the absence (left) and presence (right) of $\mathrm{HSO}_{3}{ }^{-}$ without and with $\mathrm{CB}[8]$ are shown in the inset of $\left(\mathrm{A}, 50 \mu \mathrm{M} \mathrm{HSO}_{3}^{-}\right)$and $\left(\mathrm{C}, 200 \mu \mathrm{M} \mathrm{HSO}_{3}^{-}\right)$, respectively. Also shown are the $F_{\mathrm{a}} / F_{\mathrm{i}}$ changes upon increasing the $\mathrm{HSO}_{3}{ }^{-}$or $\mathrm{H}_{2} \mathrm{~S}$ concentration (E) without and (F) with $\mathrm{CB}[8]$, respectively.

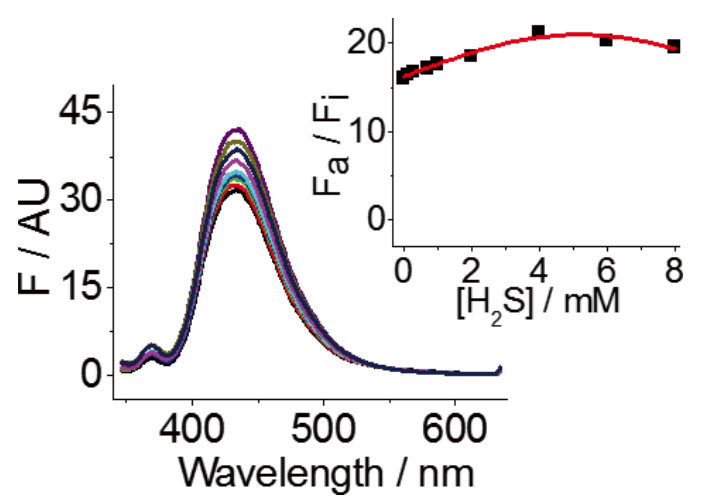

Fig. 3 Fluorescence spectra of SG $(1 \mu \mathrm{M})$ and $\mathrm{CB}[8](5 \mu \mathrm{M})$ with $\mathrm{HSO}_{3}{ }^{-}$alone $(180 \mu \mathrm{M})$ and coexisting with $\mathrm{H}_{2} \mathrm{~S}$.

To improve the response specificity of SG to $\mathrm{HSO}_{3}{ }^{-}$, we then checked the fluorescence response of $\mathrm{SG}(1 \mu \mathrm{M})$ to $\mathrm{HSO}_{3}{ }^{-}$and $\mathrm{H}_{2} \mathrm{~S}$ in the presence of $5 \mu \mathrm{M} \mathrm{CB}[8]$. As shown in Fig. 2C, the $\mathrm{CB}[8]$ addition causes a more noticeable increase and decrease in the fluorescence of SG at 435 and $544 \mathrm{~nm}$ in response to $\mathrm{HSO}_{3}{ }^{-}$at $\mathrm{pH}$ 6.2, although this host-guest encapsulation blunts the response with the linear range for the $\mathrm{HSO}_{3}{ }^{-}$response increasing up to about $200 \mu \mathrm{M}$ (Fig. 2F). This suggests that this encapsulation can expand the $\mathrm{HSO}_{3}^{-}$response range. The change in the solution color under $\mathrm{UV}$ illumination upon $\mathrm{HSO}_{3}{ }^{-}$ addition becomes much more distinct (inset of Fig. 2C). The detection limit in this case is estimated to be about $16 \mu \mathrm{M}$, assuming a signal-to-noise ratio of 3 . However, $\mathrm{H}_{2} \mathrm{~S}$ is much less efficient in decreasing the iminium band and increasing the alkanolamine band (Fig. 2D). Within the linear response range, the response slope $\left(\Delta\left(F_{\mathrm{a}} / F_{\mathrm{i}}\right) v s . \Delta C\right)$ for $\mathrm{HSO}_{3}{ }^{-}$in the presence of $\mathrm{CB}[8]$ is 45 -fold higher than that for $\mathrm{H}_{2} \mathrm{~S}$ (Fig. 2F). Furthermore, the coexistence of $\mathrm{H}_{2} \mathrm{~S}$ (up to $8 \mathrm{mM}$ ) with $180 \mu \mathrm{M}$

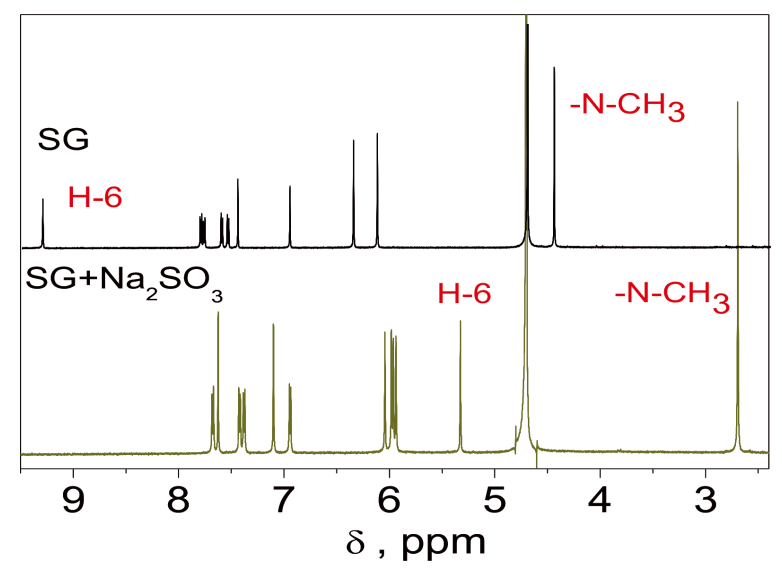

Fig. $4{ }^{1} \mathrm{H}$ NMR spectra of $\mathrm{SG}(4 \mathrm{mM})$ and its interaction with $\mathrm{HSO}_{3}{ }^{-}$ $(20 \mathrm{mM})$ in $\mathrm{D}_{2} \mathrm{O}$.

$\mathrm{HSO}_{3}{ }^{-}$only slightly increases the $F_{\mathrm{a}} / F_{\mathrm{i}}$ value (Fig. 3 ). These facts demonstrate that the $\mathrm{CB}[8]$ encapsulation can improve the selectivity of the $\mathrm{SG}$ response to $\mathrm{HSO}_{3}{ }^{-}$against $\mathrm{H}_{2} \mathrm{~S}$ because of the stronger inhibition of the nucleophilic addition ${ }^{32}$ by $\mathrm{CB}$ [8] with the sulfur atom in $\mathrm{H}_{2} \mathrm{~S}$ that has a lower electron density than that in $\mathrm{HSO}_{3}{ }^{-}$. Thus, less interference from $\mathrm{H}_{2} \mathrm{~S}$ is expected for the $\mathrm{HSO}_{3}{ }^{-}$detection. Note that upon addition of $\mathrm{HSO}_{3}{ }^{-}$or $\mathrm{H}_{2} \mathrm{~S}$ in the absence and presence of $\mathrm{CB}[8]$, the absorption band of SG almost exists at about $327 \mathrm{~nm}$ (Fig. S2), suggesting that the rariometric sensor for the $\mathrm{HSO}_{3}{ }^{-}$detection can be operated at a single excitation wavelength.

${ }^{1} \mathrm{H}$ NMR was then used to further confirm the interaction of $\mathrm{SG}$ with $\mathrm{HSO}_{3}^{-}$. As shown in Fig. 4, the ${ }^{1} \mathrm{H}$ NMR chemical shifts of $\mathrm{SG}$ alone in $\mathrm{D}_{2} \mathrm{O}$ can be assigned to $4.45\left(\mathrm{~N} 5-\mathrm{CH}_{3}\right)$, $6.13\left(\mathrm{C} 2-\mathrm{O}-\mathrm{CH}_{2}-\mathrm{O}-\mathrm{C} 3\right), 6.35\left(\mathrm{C} 7-\mathrm{O}-\mathrm{CH}_{2}-\mathrm{O}-\mathrm{C} 8\right), 6.96(\mathrm{H}-1)$, $7.45-7.81$ (H-4, H-9, H-10, H-11, H-12), and 9.30 (H-6). ${ }^{32}$ 


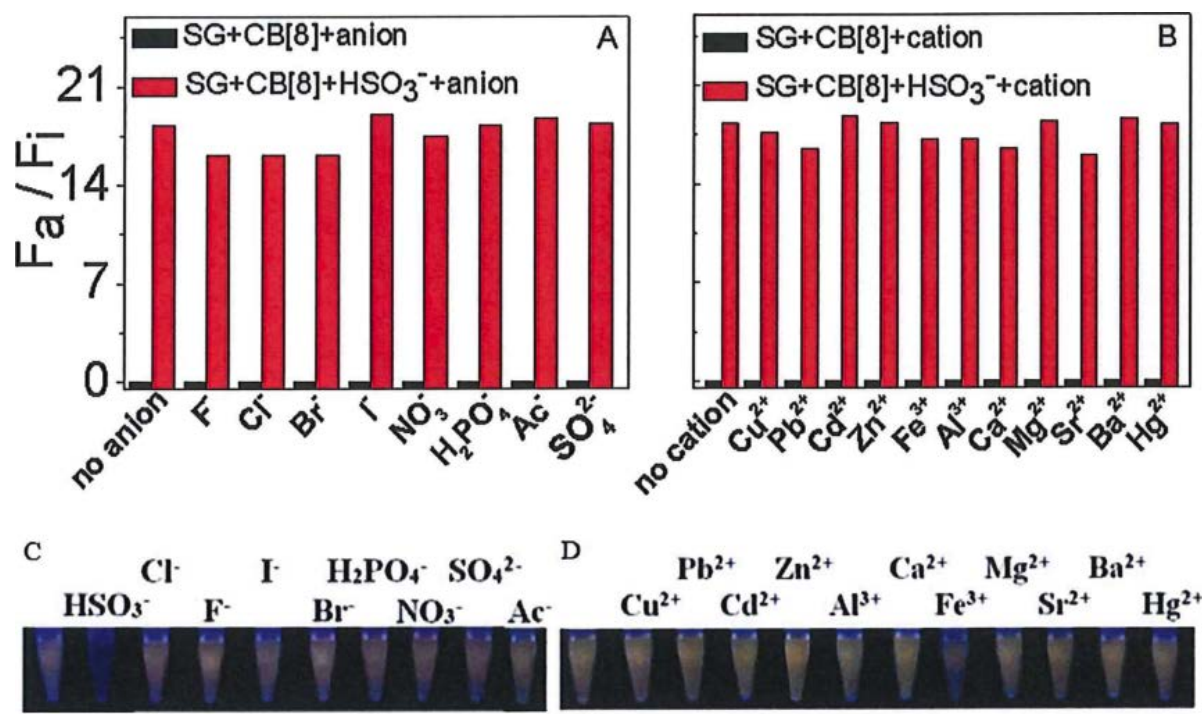

Fig. 5 Fluorescence ratio changes of $\mathrm{SG}(1 \mu \mathrm{M})$ in the presence of (A) anions $\left(\mathrm{HSO}_{3}{ }^{-}\right.$at $200 \mu \mathrm{M}$ and others at $1 \mathrm{mM}$ ) and (B) cations $(200 \mu \mathrm{M}$, EDTA $3 \mathrm{mM})$ in $50 \mathrm{mM}$ PBS (pH 6.2, $0.1 \mathrm{M} \mathrm{K}^{+}$) containing $5 \mu \mathrm{M} \mathrm{CB}[8]$. Also shown are photographs of these solutions under UV illumination in the presence of (C) anions and (D)cations, respectively.

After the addition of 5 equivalent $\mathrm{HSO}_{3}{ }^{-}$, these chemical shifts changed to $2.69\left(\mathrm{~N} 5-\mathrm{CH}_{3}\right), 5.53(\mathrm{H}-6), 5.94-6.04(\mathrm{C} 2-\mathrm{O}-$ $\mathrm{CH}_{2}-\mathrm{O}-\mathrm{C} 3$ and $\left.\mathrm{C} 7-\mathrm{O}-\mathrm{CH}_{2}-\mathrm{O}-\mathrm{C} 8\right), 6.94$ (H-1), and $7.10-7.68$ (H-4, H-9, H-10, H-11, H-12), respectively. These data suggest that the two types of protons in $\mathrm{N} 5-\mathrm{CH}_{3}$ and $\mathrm{H}-6$ experience the largest chemical environment alteration by shifting to the high field in the ${ }^{1} \mathrm{H}$ NMR upon interaction with $\mathrm{HSO}_{3}^{-}$, demonstrating that the electron cloud densities around these protons are increased. Therefore, we can conclude that the $\mathrm{C} 6=\mathrm{N} 5^{+}$group undergo a nucleophilic addition by $\mathrm{HSO}_{3}{ }^{-}$, as depicted in Scheme 1.

The effect of common anions and cations on the $\mathrm{HSO}_{3}^{-}$ response specificity was then examined. As shown in Fig. 5A, compared with the significant response for $200 \mu \mathrm{M} \mathrm{HSO}_{3}{ }^{-}$, representative anions of $\mathrm{F}^{-}, \mathrm{SO}_{4}{ }^{2-}, \mathrm{Cl}^{-}, \mathrm{I}^{-}, \mathrm{Br}^{-}, \mathrm{NO}_{3}{ }^{-}, \mathrm{Ac}^{-}$, and $\mathrm{H}_{2} \mathrm{PO}_{4}^{-}$alone in solution at $1 \mathrm{mM}$ still keep the $F_{\mathrm{a}} / F_{\mathrm{i}}$ value at the background level. The coexistence of these anions with $\mathrm{HSO}_{3}{ }^{-}$has no obvious effect on the $\mathrm{HSO}_{3}{ }^{-}$response. Note that the reductive $\mathrm{I}^{-}$is inefficient in interacting with $\mathrm{SG}$. The $\mathrm{HSO}_{3}{ }^{-}$ specificity over other anions can be discriminated by the naked eye under UV illumination (Fig. 5C). Furthermore, typical cations such as $\mathrm{Cu}^{2+}, \mathrm{Pb}^{2+}, \mathrm{Cd}^{2+}, \mathrm{Zn}^{2+}, \mathrm{Al}^{3+}, \mathrm{Ca}^{2+}, \mathrm{Fe}^{3+}, \mathrm{Mg}^{2+}$, $\mathrm{Sr}^{2+}, \mathrm{Ba}^{2+}$, and $\mathrm{Hg}^{2+}$ alone and coexisted with $\mathrm{HSO}_{3}^{-}$(each cation was at $200 \mu \mathrm{M}$ and EDTA was added to avoid the direct interaction of cations with $\mathrm{HSO}_{3}{ }^{-}$) do not induce significant changes in the $F_{\mathrm{a}} / F_{\mathrm{i}}$ value (Fig. 5B). The solution colors under UV illumination (Fig. 5D) also confirm the specificity for the $\mathrm{HSO}_{3}{ }^{-}$response.

Finally, we explored application of our method in detecting $\mathrm{HSO}_{3}^{-}$using tap water and rainwater as the typical samples. The standard addition method was used to confirm the feasibility of our method. The recoveries of six samples were close to $100 \%$ (Table S1), demonstrating that our method can be used for the real sample analysis. Therefore, our method has potential applications for the selective detection of $\mathrm{HSO}_{3}^{-}$in water samples.

\section{Conclusions}

In summary, we developed a novel fluorescent method for a selective $\mathrm{HSO}_{3}{ }^{-}$assay based on its nucleophilic addition reaction with SG. The reaction occurs at the $\mathrm{C}=\mathrm{N}^{+}$group to bring a decrease in the SG iminium fluorescence and an increase in the alkanolamine fluorescence. Thus, a ratiometric fluorescence method can be established for $\mathrm{HSO}_{3}{ }^{-}$detection. Furthermore, the host-guest encapsulation with $\mathrm{CB}[8]$ is confirmed to be an efficient way to improve the detection selectivity of $\mathrm{HSO}_{3}$ against other species including, for example, $\mathrm{H}_{2} \mathrm{~S}$. Other common anions and cations have no interference with the $\mathrm{HSO}_{3}{ }^{-}$response, suggesting a promising application of our method in real sample analysis. In this work, we first demonstrated the occurrence of the interaction of the natural benzophenanthridine alkaloid $\mathrm{SG}$ with $\mathrm{HSO}_{3}{ }^{-}$, and a ratiometric fluorescence method was developed with a large emission wavelength shift. Since $\mathrm{SO}_{2}$ exists in cells and $\mathrm{SG}$ is usually used as an anti-cancer drug, our work also demonstrates the potential $\mathrm{SG}$ pharmacology by interaction with $\mathrm{SO}_{2}$ derivatives.

\section{Acknowledgements}

This work was supported by the National Natural Science Foundation of China (Grant No. 21675142) and the National and Zhejiang Undergraduate Training Program for Innovation and Entrepreneurship (Grant No. 201810345017).

\section{Supporting Information}

Fluorescence spectra of the SG-CB $[n]$ system in the absence and presence of $\mathrm{HSO}_{3}^{-}$, and the sample analysis results. This material is available free of charge on the Web at http://www. jsac.or.jp/analsci/. 


\section{References}

1. G. Li and N. Sang, Ecotoxicol. Environ. Saf., 2009, 72, 236.

2. S. Iwasawa, Y. Kikuchi, Y. Nishiwaki, M. Nakano, T. Michikawa, and T. Tsuboi, J. Occup. Health, 2009, 51, 38.

3. K. Li, L. L. Li, Q. Zhou, K. K. Yu, J. S. Kim, and X. Q. Yu, Coord. Chem. Rev., 2019, 388, 310.

4. F. B. Yu, X. Y. Han, and L. X. Chen, Chem. Commun., 2014, 50, 12234.

5. V. S. Lin, W. Chen, M. Xian, and C. J. Chang, Chem. Soc. Rev., 2015, 44, 4596.

6. X. Li, X. Gao, W. Shi, and H. Ma, Chem. Rev., 2014, 114, 590.

7. H. Vally, N. L. A. Misso, and V. Madan, Clin. Exp. Allergy, 2009, 39, 1643.

8. J. L. Hart, Front. Biosci., 2011, 3, 736.

9. C. C. Wang, S. Feng, L. Y. Wu, S. Y. Yan, C. Zhong, P. Guo, R. Huang, X. C. Weng, and X. Zhou, Sens. Actuators, B, 2014, 190, 792.

10. J. Ding, Y. Q. Ge, and B. C. Zhu, Anal. Sci., 2013, 29, 1171.

11. S. Chen, P. Hou, J. X. Wang, and X. Z. Song, RSC Adv., 2012, 2, 10869.

12. Y. Liu, J. Nie, J. Niu, W. S. Wang, and W. Y. Lin, J. Mater: Chem. B, 2018, 6, 1973.

13. C. Y. Liu, H. F. Wu, W. Yang, and X. L. Zhang, Anal. Sci., 2014, 30, 589.

14. Y. Q. Sun, J. Liu, J. Zhang, T. Yang, and W. Gao, Chem. Commun., 2013, 49, 2637.

15. M. Y. Wu, K. Li, C. Y. Li, J. T. Hou, and X. Q. Yu, Chem. Commun., 2014, 50, 183.

16. L. Zhu, J. Xu, Z. Sun, B. Fu, C. Qin, L. Zeng, and X. Hu, Chem. Commun., 2015, 51, 1154.

17. W. Xu, C. L. Teoh, J. J. Peng, D. D. Su, L. Yuan, and Y. T. Chang, Biomaterials, 2015, 56, 1.
18. M. X. Li, W. Y. Feng, H. Y. Zhang, and G. Q. Feng, Sens. Actuators, B, 2017, 243, 51.

19. W. L. Wu, Z. Y. Wang, X. Dai, J. Y. Miao, and B. X. Zhao, Sci. Rep., 2016, 6, 25315.

20. F. Wu, Y. W. Sun, Y. Shao, S. J. Xu, G. Y. Liu, J. Peng, and L. L. Liu, PLoS One, 2011, 7, e48251.

21. L. H. Zhang, H. Liu, Y. Shao, C. Lin, H. Jia, G. Chen, D. Z. Yang, and Y. Wang, Anal. Chem., 2015, 87, 730.

22. Y. Wang, Y. H. Hu, T. Wu, X. S. Zhou, and Y. Shao, Anal. Chem., 2015, 87, 11620.

23. C. Lin, G. H. Wu, K. B. Wang, B. Onel, S. Sakai, Y. Shao, and D. Z. Yang, Angew. Chem. Int. Ed., 2018, 57, 10888.

24. N. Ahmad, S. Gupta, M. M. Husain, K. M. Heiskanen, and H. Mukhtar, Clin. Cancer Res., 2000, 6, 1524.

25. Z. Ding, S. C. Tang, P. Weerasinghe, X. Yang, A. Pater, and A. Liepins, Biochem. Pharmacol., 2002, 63, 1415.

26. M. M. Chaturvedi, A. Kumar, B. G. Darnay, G. B. N. Chainy, S. Agarwal, and B. B. Aggarwal, J. Biol. Chem., 1997, 272, 30129.

27. J. Huh, A. Liepins, J. Zielonka, C. Andrekopoulos, B. Kalyanaraman, and A. Sorokin, Cancer Res., 2006, 66, 3726.

28. M. Hossain, A. Y. Khan, and G. S. Kumar,. J. Chem. Thermody., 2012, 47, 90.

29. M. Maiti and G. S. Kumar, Med. Res. Rev., 2007, 27, 649.

30. M. Maiti, R. Nandi, and K. Chaudhuri, Photochem. Photobiol., 1983, 38, 245.

31. A. K. Yatsimirsky, Nat. Prod. Commun., 2012, 7, 369.

32. Z. Miskolczy, M. Megyesi, G. Tarkanyi, R. Mizsei, and L. Biczok, Org. Biomol. Chem., 2011, 9, 1061.

33. C. F. Li, L. M. Du, and H. M. Zhang, Spectrochim. Acta, Part A, 2010, 75, 912 .

34. K. Hirakawa and T. Hirano, Photochem. Photobiol., 2008, 84, 202.

35. S. J. Barrow, S. Kasera, M. J. Rowland, J. del Barrio, and O. A. Scherman, Chem. Rev., 2015, 115, 12320. 